\title{
UMA BREVE PERSPECTIVA SOBRE VERDADE E MENTIRA
}

Roni Lenon da Silva ${ }^{1}$

Resumo: O objetivo deste escrito é disponibilizar uma discussão do ensaio Sobre verdade e mentira no sentido extramoral (1873) escrito pelo filósofo alemão Friedrich Nietzsche, fazendo uma breve relação final com uma obra do mesmo período O nascimento da tragédia a partir do espírito da música (1872).

Palavras chave: Linguagem. Sonho. Verdade.

Abstract: The purpose of this writing is to provide a discussion of On Truth testing and lie in the extra-moral sense ( 1873) written by the German philosopher Friedrich Nietzsche, making a final brief relationship with a work of the same period The Birth of Tragedy from the spirit of music (1872).

Keywords: language. Dream. truth.

\section{Siglas para citações das obras:}

GT/NT - Die Geburt der Tragödie (O nascimento da tragédia)

DW/VD - Die dionysische Weltanschauung ( $A$ visão dionisíaca do mundo)

WL/VM - Über Wahrheit und Lüge im aussermoralischen Sinn (Sobre verdade e mentira no sentido extramoral.

Sobre verdade e mentira no sentido extramoral é um ensaio ditado por Nietzsche em junho de 1873 para o seu amigo Carl Von Gersdorff. Neste escrito, o filósofo alemão explora o problema da procedência do impulso à verdade.

Neste contexto, o conhecimento (intelecto) é apresentado como uma invenção humana usada como instrumento de conservação por meio da dissimulação. Segundo Nietzsche, sua procedência é acidental, não havendo nenhuma meta para o mesmo em relação a natureza, deste modo, sua aniquilação também pode ser acidental e insignificante, já que o conhecimento ocupa uma pequena parcela de tempo na "[...] história universal [...]" (WL/VM, $\S 1)$. Entretanto, essas características habitualmente são ofuscadas pelo engano

\footnotetext{
${ }^{1}$ Aluno regular do Programa de mestrado da Universidade Estadual do Oeste do Paraná.
} 
de si, o esquecimento, o orgulho e a vaidade. O problema do impulso à verdade surge neste sentido, pois se torna inviável o homem almejar isso, quando se assume as condições dos instrumentos (sensação e intelecto) para obter o que deseja, além disso a argumentação deste texto nega a existência da verdade.

A necessidade e a vontade do homem de paz na vida social formam uma possível via de esclarecimento ao problema do ensaio: "Esse acordo de paz ${ }^{2}$ traz consigo, porém, algo que parece ser o primeiro passo rumo à obtenção daquele misterioso impulso à verdade" (WLNM, §1). No âmbito social a "verdade" e a "mentira" são impostas através da valoração e a nomeação das coisas, isto é, uma limitação de modos "corretos" para se referir a efetividade. A mentira aparece quando o homem abusa destes modos, com o uso de palavras que não se direcionam à nenhuma efetividade natural. O problema deste uso na sociedade são os possíveis danos que o mesmo pode causar, por exemplo: o

\footnotetext{
${ }^{2}$ No texto há diversas referências filosóficas, a primeira se refere ao mundo platônico das formas. "[...] como se na natureza, além das folhas, houvesse algo que fosse "folha", tal como uma forma primordial de acordo com a qual todas as folhas fossem tecidas [...]" (WL/VM, §1). Um ponto importante destacado por Heidegger, em relação a este tema, é a inversão do platonismo na obra madura de Nietzsche. O que está em jogo acerca de Platão é a teoria das formas: o modo como Platão concebe o ente segundo Heidegger. Platão pondera o conhecimento como adequação: o ente força aquele que estima conhecê-lo a render-se a ele. $\mathrm{O}$ ser em Platão são as formas, todo conceber do ente é primeiramente perpassado por este âmbito, denominado como suprassensível. O Mundo concebido de forma puramente sensível é o mundo das facas, gavetas ou casas, em que o ente não percebe a si: “[...] o sensível precisa ser mensurado a partir do suprasensível; o não-ente tem a sombra e o resto de ser do verdadeiramente ente" (HEIDEGGER, 2010, p. 140). Platão não nega a existência do mundo sensível, mas afirma que ele só é possível por via do suprassensível. No que consiste afinal a inversão nietzschiana do platonismo? Considera-se que, para Platão o suprassensível tem supremacia sobre o sensível, a inversão é edificada efetivamente neste ponto quando o sensível passa a ser superior ao suprassensível: “[...] abalo do primado do supra-sensível como ideal. O ente, isso que ele é, não pode ser avaliado segundo o que ele deveria e poderia ser" (HEIDEGGER, 2010, p. 140). Outra possível relação do ensaio são algumas semelhanças terminológicas com a metáfora arquitetônica da primeira meditação cartesiana: "[...] começar tudo novamente a partir dos fundamentos, se pretendesse estabelecer algo sólido e duradouro nas ciências" (DESCARTES, 1999, p. 250). E no parágrafo seguinte: "[...] a destruição dos alicerces provoca inevitavelmente o desmoronamento de todo edifício [...]" (DESCARTES, 1999, p. 250). Já em Sobre verdade e mentira: “[...] o grande edifício dos conceitos [...]" (WL/VM, §1). Novamente na segunda parte do ensaio: "Aquele enorme entablamento e andaime de conceitos [...]" (WL/VM, §2). Outra relação é com algumas partes argumentativas do capítulo XIII do Leviatã de Hobbes. Para Hobbes a condição de "[...] guerra de todos os homens contra todos os homens [...]" (HOBBES, 1979, p. 77) possui três causas, sendo elas, a competição, a discórdia e a glória. Para sair deste estado natural e de medo constante o homem aceita um acordo artificial de paz, em que restringe parte de sua liberdade perante a lei. Já em Sobre verdade e mentira: "Enquanto o indivíduo, num estado natural das coisas, quer preservar-se contra outros indivíduos, ele geralmente se vale do intelecto apenas para a dissimulação: mas, porque o homem quer, ao mesmo tempo, existir socialmente e em rebanho, por necessidade e tédio, ele necessita de um acordo de paz e empenha-se então para que a mais cruel bellum omnium contra omnes ao menos desapareça de seu mundo" (WL/VM, §1). Além destas referências há outras, por exemplo, em Schopenhauer, Kant, Heráclito, Tales e os estoicos.
} 
golpe do bilhete premiado, "[...] então a sociedade não confiará mais nele e, com isso, tratará de excluí-lo" (WL/VM, §1).

A vontade de verdade também pode ser problemática quando se indaga pela relação entre linguagem e efetividade: "[...] as designações e as coisas se recobrem?" (WLNM, §1). Em outras palavras, as convenções da linguagem são expressões "verdadeiras" da efetividade? Há uma ressonância entre elas? O modo como Nietzsche conceitua a "palavra" incita a suspeita de uma resposta negativa. O primeiro aspecto é o esquecimento do homem a respeito de sua condição de criador de palavras; ele impõe a si e a natureza designações e conceitos, e posteriormente se ilude com essa procedência, acreditando que estas expressões são próprias das coisas e apenas descobertas por ele, isto é, verdades. Outro argumento que problematiza a possibilidade de uma "[...] expressão adequada [...]" (WL/VM, §1) da efetividade é a pluralidade de idiomas, pois como poderia existir uma relação verdadeira entre as palavras e as coisas se existem diferentes modos de expressar essa relação que são valorados como verdadeiros, dependendo o âmbito em que o indivíduo vive?

A linguagem é um instrumento que expressa e em alguns casos possibilita a relação do homem com a natureza, mas ela não expressa o que é "verdadeiramente" o "homem" e a "natureza". Para Nietzsche a procedência das palavras irrompe de um processo duplo e metafórico: "De antemão, um estímulo nervoso transposto em uma imagem! Primeira metáfora. A imagem por seu turno, remodelada num som! Segunda metáfora" (WL/VM, §1). Por exemplo, quando um indivíduo que é surpreendido por outro num ataque, porventura, inicialmente visualiza a possível arma em questão, formando uma imagem mental (primeira metáfora), posteriormente, podendo reagir com um insulto ou um pedido de socorro (segunda metáfora), como possíveis expressões para o estímulo inicial. Já a procedência dos conceitos se faz pela utilização das mesmas palavras para coisas semelhantes, ao invés de iguais; a vivência da dor é individual, mas o conceito de "dor" é geral. "Todo conceito surge pela igualação do não-igual" (WL/VM, §1). O esquecimento das diferenças e vivências individuais através da abstração possibilita essa generalização. 
Após está argumentação Nietzsche apresenta e responde uma nova pergunta, retomando a argumentação da verdade no contexto social3: "O que é, pois, a verdade?" (WL/VM, §1). Para o filósofo, o sentimento de verdade é o resultado do uso habitual e útil de certos modos de se referir as coisas, que através da hereditariedade e a tradição podem se tornar obrigatórios em determinados grupos sociais. Deste modo, a verdade possui um aspecto moral, pois se obriga a usar certas convenções, e o sentimento de verdade irrompe quando se obedece a isso. Além disso, o indivíduo que se submete a este uso, porventura, recebe a confiança da sociedade que é outro elemento catalisador do sentimento de verdade. $O$ âmbito abstrato e ilusório passa a ser o governante do âmbito intuitivo: "[...] criar um novo mundo de leis, privilégios, subordinações, delimitações, que agora faz frente ao outro mundo intuitivo [...] como o mundo regulador e imperativo" (WL/VM, §1).

Esta capacidade de criar metáforas sobre a efetividade, para Nietzsche é uma das diferenças centrais entre o animal e o homem. O pensador exemplifica esta diferença com a abelha; a criação de seu mel depende da natureza, já o homem cria o seu mundo conceitual a partir de si, um mundo antropomórfico. É neste sentido que Nietzsche parafraseia a expressão de Protágoras: "[...] ter o homem por medida de todas as coisas [...]" (WL/VM, §1). Esse intento de metamorfosear o mundo em homem é de grande interesse para o homem da ciência, entretanto, é um empreendimento destinado ao fracasso, pois para o filósofo entre sujeito e objeto não há nenhuma assimilação, ou relação casual necessária, apenas uma relação estética que se faz por meio da criação de metáforas.

$\mathrm{Na}$ segunda e última parte do ensaio, Nietzsche se ocupa com a diferenciação entre o homem racional (pesquisador/cientista) e o homem intuitivo (artista/grego homérico), que se refere ao modo como eles tentam "[...] imperar

\footnotetext{
${ }^{3}$ Além disso, neste contexto, Nietzsche destaca que ainda não há uma tese para o seu problema inicial. Outro ponto que é pertinente destacar sobre a relação entre problema e tese deste ensaio é que Nietzsche parece se desviar do próprio problema, mostrando uma fragilidade estrutural e argumentativa. O problema inicial do ensaio aparece formulado de duas maneiras: "[...] como pôde vir à luz entre os homens um legítimo e puro impulso à verdade" (WL/VM, §1). E no final do mesmo parágrafo: "Então de onde viria o impulso à verdade no mundo inteiro, nesta constelação?" (WL/VM, §1). A argumentação dos próximos parágrafos se direciona mais para a relação entre natureza e linguagem, e Nietzsche lança outra pergunta (“O que é, pois, a verdade?” (WLVM,$\S 1)$ ) sem antes disponibilizar nenhuma tese para o problema inicial até o fim do ensaio.
} 
sobre a vida [...]" (WLNM, §2). O primeiro é fiel ao uso sistemático dos conceitos, ou seja, "[...] um novo mundo firme e regular [...]" (WL/VM, §2), pois seu intento se direciona à verdade. Este tipo homem se torna escravo de suas próprias criações conceituais, tendo que ser fiel a sua deformação e medida do mundo, sem poder assumir a total dissimulação da relação conceitual. Deste modo, a pesquisa científica se torna um exercício infeliz.

Já o segundo tipo de homem, na sua criação desfruta de um prazer semelhante ao prazer onírico. "O dia desperto de um povo miticamente inspirado, como, por exemplo, os antigos gregos, é, de fato, mais semelhante ao sonho do que o dia do pensador que se tornou cientificamente sóbrio [...]" (WL/VM, §2). A liberdade da arte em relação a verdade possibilita uma diferente relação conceitual, como é o caso da poesia homérica. A relação entre sonho e este tipo de criação é a inconstância da linearidade e a possiblidade de eventos e vivências, que se diferenciam do mundo conceitual do homem desperto. Essa liberdade do intelecto na arte está ligada a outra característica do mesmo, a dissimulação, que por não causar possíveis danos não é atada ao convencional ou "verdadeiro".

Esta relação entre sonho e arte nos gregos é amplamente explorada em O nascimento da tragédia. Nesta obra, Nietzsche apresenta alguns indícios a respeito da causalidade onírica ao se referir aos gregos:

[...] dada a incrivelmente precisa e segura capacidade plástica que eram dotados os seus olhos, unida [à] luminosa e sincera paixão pela cor, não é possível abster-se, para a vergonha de todos os pósteros, de supor que também os seus sonhos possuíam causalidade lógica de linhas e de contornos, de cores e de grupos, uma sequência de cenas semelhantes a seus melhores baixos-relevos (GT/NT, §2).

A causalidade onírica se constitui de imagens que produzem cenas; acontecimentos que não possuem uma relação causal entre si, a única causalidade é circunscrita às próprias cenas. Devido a essa desvelação de cenas, a memória dificilmente grava o que foi sonhado e, quando fixa, é por pouco tempo. A falta de fixação torna a dinâmica onírica sempre nova ao humano, dificultando a possibilidade de avaliação do sonho, no sonho, sendo o imagético apenas vislumbrado, sem a pretensa interferência psicológica vigente 
na vigília. "Gozamos no entendimento imediato da figura, todas as formas nos falam; nada há de indiferente e desnecessário" (DW/ND, §1).

$\mathrm{Na}$ efetividade (Wirklichkeit) onírica não há possibilidade e nem necessidade do indivíduo outorgar sentido à concatenação e ao fluxo dos acontecimentos. O resquício conceitual do sonho é empregado apenas para a identificação das imagens presentes. O sonho é um campo fenomênico que se mostra para o indivíduo através de insinuações enigmáticas, representando a possibilidade da construção e da relação entre mundo e homem sem a necessidade da interferência consciente.

Na mudança entre o âmbito da vigília e o onírico há uma substituição do modo da linguagem enquanto faculdade prescrita de sentido, na qual o conceito transmuta-se em símbolo. O símbolo é a forma dizendo a si mesma, sem mediação, ou velamento conceitual, que constituem mecanismo com causas e efeitos lineares e dependentes. No sonho há apenas a causalidade imagética constituída pela dinâmica temporal vigente. O sonho irrompe no presente, é sem passado e revela para o indivíduo uma realidade circunscrita em qualquer âmbito temporal. Deste modo, os sonhos não são projetados previamente pela faculdade imagética, com a pretensão de que posteriormente possam ser vivenciados (mesmo que de forma semelhante) como alguns acontecimentos da vigília.

Na vigília o acesso do indivíduo ao passado pelo presente proporciona o desfrute projetivo de uma configuração futura da efetividade, disponibilizando paralelamente uma mínima estabilidade sobre a condução dos possíveis acontecimentos que podem se efetivar; processo este irrealizável no desfrute onírico, que impossibilita a possibilidade de preocupação, pois o sonhador ao mesmo tempo em que projeta, o sonho já se torna sonho. Entre possibilitar e vivenciar aparece uma difícil fenda acerca do estatuto constitutivo do sonho. $O$ sonho é um momento singular, que para se constituir depende dos fragmentos passados que foram demarcados pela consciência de cada indivíduo, no entanto, a própria fonte da qual emana estes resquícios de memória, não pode configurá-las; concebendo-as como efetividades não limitadas no âmbito racional. Pode-se inferir fragilmente que o sonho é a efetivação de pensamentos não assumidos no seu efetivar enquanto pensamentos. 
Em relação ao desfrute desse estado, há dois tipos de indivíduo: o homem comum e $\mathrm{o}$ artista. $\mathrm{O}$ primeiro se comporta de modo passivo, considerando $\mathrm{O}$ sonho apenas como um meio letárgico, que contrabalanceia seu tédio existencial na vigília. Já o artista desfruta de uma alternância de passividade e atividade ao relacionar a experiência onírica com a vigília. O irromper do prazer no onírico acontece devido ao resquício de individualidade ainda presente, representado pela relação do que percebe e do que é percebido. A aceitação autêntica da dor e do prazer é possível devido a esta relação, que faz indivíduo perceber o sonho como ilusão (Schein), por isso "[...] o homem, à noite, através da vida, deixa que o sonho lhe minta, sem que seu sentimento moral jamais tentasse impedi-lo" (WL/VM, §1).

Quando o elemento ilusório do sonho se torna inoperante, inicia-se o processo patológico, em que a realidade onírica se torna equivalente à realidade da vigília. No que concerne ao artista plástico, o sonho não denota apenas como um meio de prazer, mas também é uma via para a criação, que consiste na transmutação imitativa dos elementos da realidade onírica para além de sua circunscrição. "Enquanto, portanto, o sonho é um jogo do homem individual com o real, a arte do escultor (em sentido lato) é o jogo com o sonho" (DW/VD, §1). O sonho disponibiliza a quintessência para toda a arte plástica e uma parte da poesia. O poeta procura entender e interpretar, o artista plástico tenta transpor, com o objetivo de recriação do mundo, através de uma justificativa que ultrapasse os limites da esfera conceitual, instaurada e articulada pela consciência.

O poder de imaginação e encantamento (Verzauberung) do artista plástico é superior em comparação com o homem comum, esta capacidade lhe possibilita absorver por mais tempo e com mais vigor a dinâmica onírica, ao ponto de recriá-la. "Enquanto a estátua continuar pairando como imagem de fantasia diante dos olhos do artista, ela se manterá como real. No momento em que traduz a imagem para o mármore, ele joga com o sonho" (DW/VD, §1). A objetivação não representa o fim do encantamento, ela é apenas uma transformação. A continuação do sonho na vigília possibilita o objeto artístico, deste objeto se abre uma nova via para o encantamento, no entanto, mais fraca desfrutada tanto por aquele que cria como por aquele que contempla. 
Na efetividade onírica há duas vias de justificar a existência. A primeira consiste no viver efetivo do que é projetado, mas impossibilitado de ser vivido na condição desperta do indivíduo, devido às particularidades de sua história singular, e o modo como elas se inserem na história universal; processo que em alguns casos se constitui contrário ao querer individual, sendo este satisfeito efetivamente apenas em sonho. A segunda via refere-se às projeções disponibilizadas no sonho, que, quando revividas posteriormente como obscuras reminiscências, são adicionadas à vigília como possíveis modos de configurar, ou re-configurar a existência. Deste modo, sonho e vigília contrastados incitam e despertam a criação no segundo âmbito, como, por exemplo, na arte plástica e na poesia.

\section{Referências bibliográficas}

Textos de Nietzsche:

NIETZSCHE, Friedrich: $A$ visão dionisíaca de mundo e outros textos da juventude. Tradução de Marcos Sinésio P. Fernandes e Maria Cristina S. de Souza. São Paulo: Martins fontes, 2005.

. O nascimento da tragédia: ou helenismo e pessimismo; tradução, notas e posfácio: J. Guinsburg. São Paulo: companhia das Letras, 2007.

Sobre verdade e mentira: no sentido extramoral. Organização e tradução: Fernando de Moraes Barros. São Paulo. Hedra, 2008.

Outros textos:

DESCARTES, René. Meditações. Trad: Corvisieri. Editora Abril cultural, 1999 (Coleção os pensadores).

HEIDEGGER, Martin. Nietzsche I. Trad: Marco Antônio Casanova. Rio de Janeiro, 2010.

HOBBES, Thomas. Leviatã: ou matéria, forma e poder de um estado eclesiástico e civil. Trad: João Paulo Monteiro e Maria B. Nizza da Silva. Editora Abril cultural, 1979 (Coleção os pensadores).

SCHOPENHAUER, Arthur. O mundo como vontade e como representação. Tomo I. Tradução, notas, apresentação, índice de Jair Barboza. São Paulo, Editora UNESP, 2005. 
